\title{
Flood disturbance and riparian species diversity on the Colorado River Delta
}

\author{
SCOTT D. TIEGS ${ }^{1,2, *}$, JOHN F. O'LEARY ${ }^{1}$, MOLLY M. POHL ${ }^{1}$ \\ and CARRIE L. MUNILL ${ }^{1}$ \\ ${ }^{1}$ Department of Geography, San Diego State University, San Diego, CA 92182-4493, USA; ${ }^{2}$ Current \\ address: Department of Limnology, EAWAG/ETH, Limnological Research Center, CH-6047 \\ Kastanienbaum,Switzerland; *Author for correspondence (e-mail: scott.tiegs@eawag.ch)
}

Received 4 December 2002; accepted in revised form 12 January 2004

Key words: Channel change, Flood disturbance, GIS, Lower Colorado River, Restoration, Riparian species diversity

Abstract. We investigated the influence of channel migration and expansion on riparian plant species diversity along the lower Colorado River near the United States-Mexico border. Using repeat aerial photography in a GIS we identified and classed areas of low, moderate, and high disturbance frequency caused by channel expansion and migration. Replicate vegetation plots $(12 \mathrm{~m} \times 12 \mathrm{~m})$ were sampled in each of the three disturbance classes. One-way ANOVA was used to test for differences in species richness, species diversity (using the Shannon-Weiner Index) and overall percent ground cover of plants between the three disturbance classes. Regardless of disturbance class, plots were dominated by trees or shrubs, especially the non-native Tamarix ramosissima, as well as Pluchea sericea, Baccharis salicifolia and Salix goodingii. Clearly woody species constitute the great bulk of overall species richness, percent ground cover, and species diversity $\left(H^{\prime}\right)$ in each disturbance group. No overall statistically significant differences were revealed among the disturbance groups for values of species richness, percent ground cover, or the Shannon-Wiener Index, though paired contrasts of means revealed that total percent ground cover on low disturbance plots was significantly higher than on moderately disturbed plots. Spatial and temporal variability in riparian diversity in the study area appears to hinge on factors other than disturbance frequency such as salt or drought stress. Alternately, our results could be interpreted as suggesting that in the presence of intensive flow regulation, disturbance plays a secondary role to ecological stresses, similar to that demonstrated by others. Intentional flood pulses are advocated as a restorative management strategy for improving plant productivity, management of exotic species (particularly T. ramosissima), and restoration of overall biodiversity.

\section{Introduction}

Riparian ecosystems are among the most diverse, dynamic and complex biophysical habitats on the terrestrial Earth (Naiman et al. 1993). Moreover, these ecosystems attenuate flooding, maintain elevated water tables, improve water quality, and thus provide valuable human and ecological services (Patten 1998). The integrity of riparian landscapes is maintained by disturbances (Gurnell 1995; Poff et al. 1997). Because of its ecotonal nature and position in the landscape, riparian vegetation experiences disturbances associated with both aquatic systems (e.g., channel widening and alluviation) and uplands (e.g., fire and windthrow) (Malanson 1993; Johnson 2000). Of these disturbance types, those caused by flooding are most commonly researched (e.g., Barnes 1997; Bendix 1997; Pollock et al. 1998; Cowell 
and Dyer 2002) and generally considered to be the most important in riparian landscapes settings.

The role of flood disturbance in governing riparian plant diversity has been examined by others, but as Bendix (1997) noted, with ambiguous results. When exploring relationships between flooding events and riparian diversity, researchers often use proxies for flood disturbance (Ward 1998). Pollock et al. (1998) used inundation frequency as a surrogate for disturbance and found maximal richness at sites of moderate flood frequency. However, Deiller et al. (2001) compared three riparian sites with different flood histories on the Rhine River and found maximized diversity levels on the least frequently flooded areas. Bendix (1997) demonstrated a positive relationship between diversity and unit stream power on a tributary of the Santa Clara River in southern California. In that study Bendix found a negative relationship with the same parameter on an adjacent tributary. Several studies used position within the watershed (i.e., headwaters, mid-reaches, lower reaches) as a proxy for flood magnitude (Nilsson et al. 1988, 1989, 1991; Decamps and Tabacchi 1992; Bendix 1997). Their research also yielded sometimes inconsistent results. These and other disagreements in the ecological literature have caused some to conclude that disturbance is not among the most important factors that affect species diversity (Mackey and Currie 2001).

Researchers possibly have relied on surrogates for flood disturbance rather than direct disturbance measurements because disturbance is difficult to quantify in natural settings (Pollock et al. 1998) and awkward to map (Muller 1997). Phenomena that cause mortality to one species may fail to do so to another. Disturbances are not always visible, and the effect of the disturbance may be delayed. Moreover, the distinction between stress and disturbance is somewhat arbitrary. Despite the challenges of measuring flood disturbance, the use of surrogates may be inherently problematic. When using proxies for flood disturbance such as unit stream power and discharge magnitude, researchers assume a direct relationship with disturbance. However, the disturbance induced by a flood does not hinge solely on flood parameters. The degree to which a site resists flood disturbance relates to myriad variables, including, but not limited to: (1) size of substrate, (2) degree of substrate imbrication, (3) particle shape and size, (4) phenology and age of the vegetation, (5) moisture content of substrate, (6) cohesion of substrate and (7) changes in channel geometry that occur during the flood (USGS 1989). We feel that some of the inconsistent results observed in flood disturbance/riparian diversity studies may stem from the use of disturbance proxies rather than direct disturbance measurements.

Very few quantitative studies document the influence of dams and flood discharge alteration on plant diversity patterns in Sonoran riparian ecosystems (Stromberg and Chew 2002). In this research we use repeat historical aerial photography and geographic information systems (GIS) to quantify and map flood disturbance to riparian vegetation on the Colorado River delta. Since a stream channel represents a mobile zone where flow occurs with sufficient force and frequency to deter the presence of riparian vegetation, it can be viewed as a zone of disturbance. In a GIS we delineated the channel of the lower Colorado River on aerial photographs from different years 


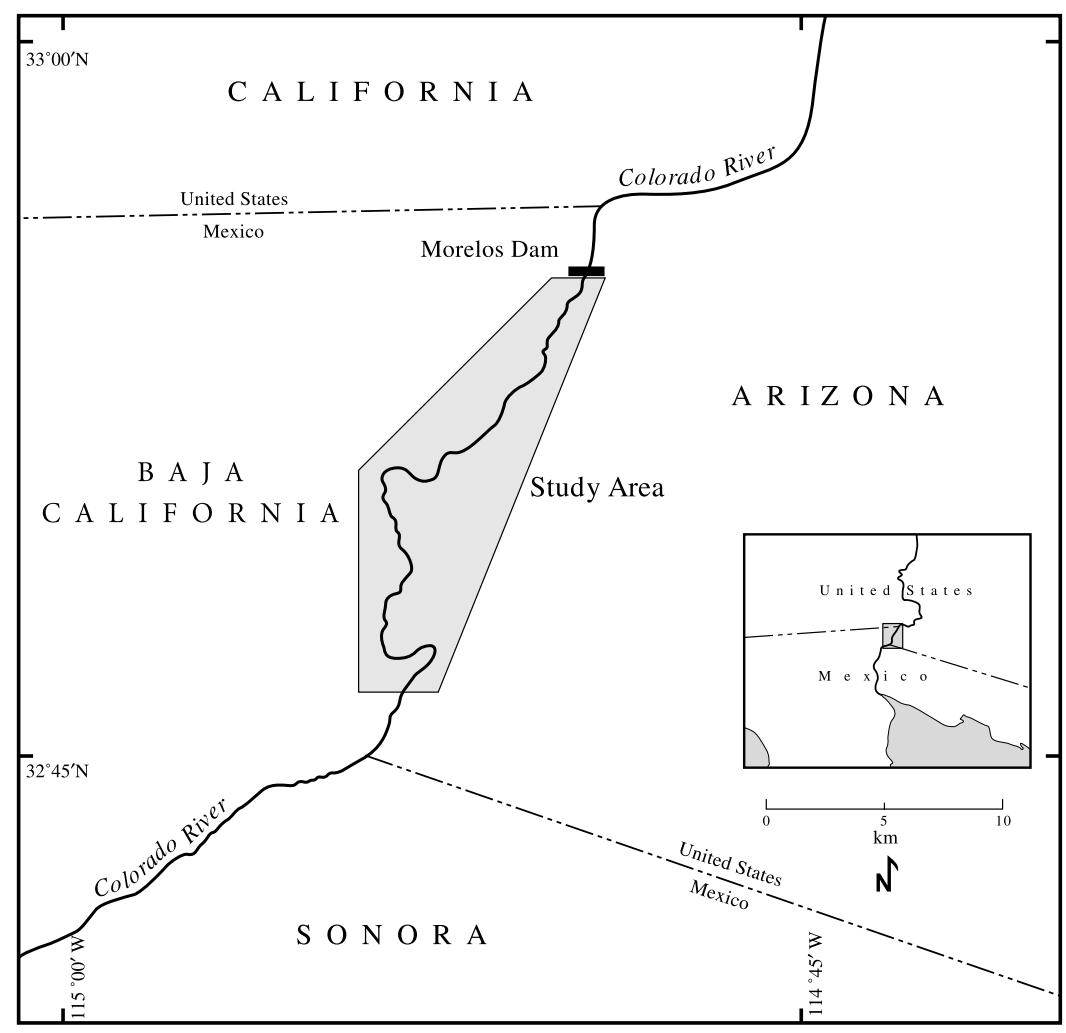

Figure 1. Location of the study area along the limitrophe reach of the lower Colorado River.

and constructed a disturbance probability model (DPM) similar to the locational probability model of Graf (2000). The DPM shows the likelihood that a given point or area was disturbed by flooding during the timeframe of the study. The DPM coupled with vegetation data acquired by field sampling allowed us to examine patterns of plant species diversity associated with level of flood disturbance. Results of such research hold implications not only for theoretical understanding of the processes and phenomena governing plant species diversity, but also for resource managers who are increasingly using intentional flood releases as a means of restoring degraded riparian ecosystems.

\section{Study area}

This research was conducted on the limitrophe reach (i.e., situated along the international boundary) of the lower Colorado River that flows southward from Morelos Dam to the Southern International Boundary (Figure 1). The approximately $30 \mathrm{~km}$-long limitrophe reach is where the Colorado River first encounters 


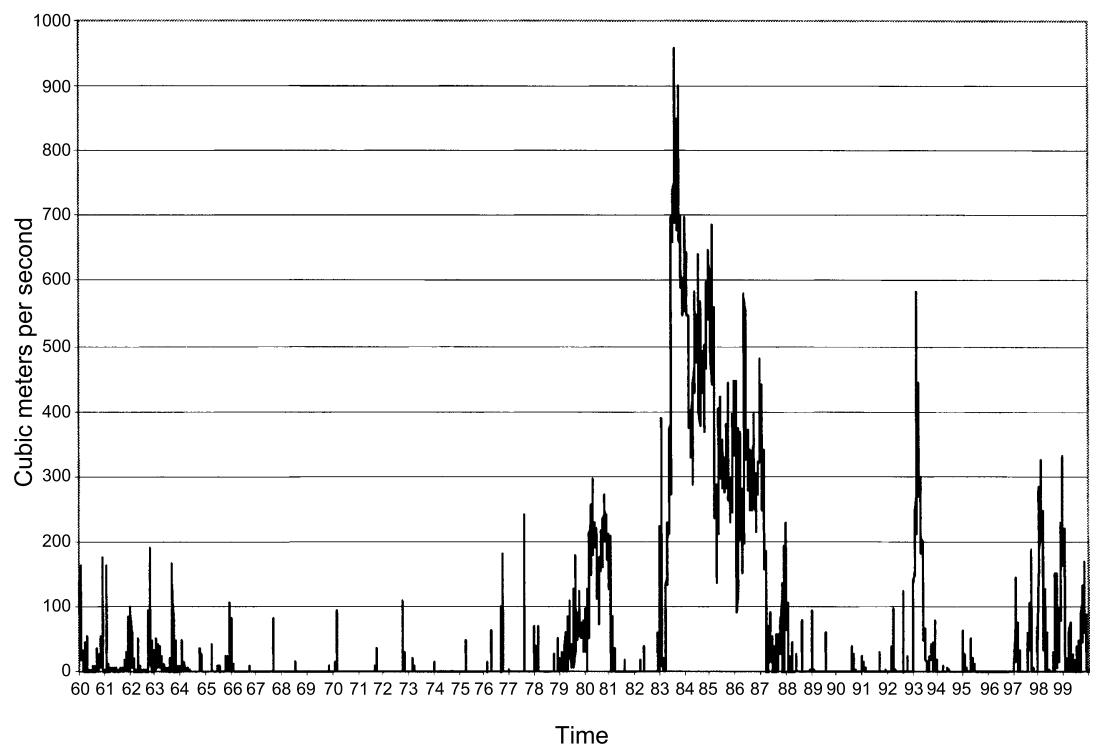

Figure 2. Discharges to the limitrophe reach 1960-2000. Discharge values shown here were obtained by subtracting discharges from the Central Feeder Canal, located at Morelos Dam from releases across the Southern International Boundary. Error in estimating discharges to the limitrophe reach is likely expressed as an overestimation of flow. Sources of error include losses to groundwater, evaporation and storage behind Morelos Dam.

the deposits comprising its delta. It also functions politically as the boundary between the United States and Mexico.

Situated in the Sonoran Desert, the climate of the limitrophe reach is characterized by extreme heat and aridity. Mean annual precipitation is approximately $6 \mathrm{~cm}(\mathrm{CI}-$ MIS 2002). Ambient air temperatures above $40^{\circ} \mathrm{C}$ commonly occur during summer months. Low precipitation and high temperatures yield annual pan evaporation rates in excess of $2 \mathrm{~m}$ (CIMIS 2002).

Historically, discharges of the limitrophe reach (drainage area $647,000 \mathrm{~km}^{2}$ ) were highly variable and unpredictable. Flood flows were occasionally in excess of $8500 \mathrm{~m}^{3} \mathrm{~s}^{-1}$ and as low as $0 \mathrm{~m}^{3} \mathrm{~s}^{-1}$ (Sykes 1937). Mean annual discharges were on the order of $1.8 \times 10^{10} \mathrm{~m}^{3}$ (Cohen et al. 2001). Flow variability and unpredictability led to the construction of many large dams on the mainstem of the Colorado River. These dams afforded flood and drought protection, and provided a source of renewable energy. However, these dams were not without adverse ecological consequences.

Contemporary flows through the limitrophe reach have been decreased by $75 \%$ (Pitt et al. 2000). Most of the vast freshwater and brackish wetlands that blanketed the Colorado River delta were reduced to barren mudflats or stands of the exoticinvasive plant species Tamarix ramosissima (plant nomenclature according to Hickman 1993). For accounts of the historic Colorado River Delta see Sykes (1937), and Glenn et al. (1996, 2001). Flows to the limitrophe reach were especially rare from the early 1960s to the early 1980s (Figure 2). This time span coincided with the 
filling of Lake Powell (storage capacity on the order of $1.9 \times 10^{10} \mathrm{~m}^{3}$ ) which was the last reservoir constructed on the mainstem of the Colorado River. Since the filling of Lake Powell, the hydrologic regime of the lower Colorado River has more closely approximated the pre-dam regime (Figure 2). Numerous flooding episodes have restored riparian vegetation on the Colorado River delta, including the limitrophe reach. These floods have typically been associated with El Niño-Southern Oscillation conditions yielding above average annual precipitation in the Colorado River basin.

Vegetation of the contemporary limitrophe reach consists largely of T. ramosissima, Pluchea sericia, Populus fremontii, Salix gooddingii, and Baccharis salicifolia. This type of riparian vegetation constitutes one of the most valuable wildlife habitats in the lower Colorado drainage (Luecke et al. 1999). While only about 100 ha of this vegetation type grows upstream of the Colorado River delta, the delta sustains approximately 1800 ha (Zamora-Arroyo et al. 2001). Given the demonstrated resilience of this vegetation, government agencies in the United States and Mexico are now considering the possibility of intentional flood releases intended to maintain and restore the riparian vegetation of the Colorado River delta. Understanding how flood releases affect riparian diversity in this area could help tailor a flood regime such that riparian diversity is maximized.

During the past 25 years, the stream channel of the limitrophe reach, comprised largely of easily entrainable fine sands, has adjusted its planform character to episodes of high and low flow primarily through channel expansion and contraction (Tiegs and Pohl, in press). Channel expansion was sometimes significant, with channel width and area more than doubling in response to the extreme hydrologic events of the early and mid-1980s (Tiegs and Pohl, in press). This and several other episodes of widening constitute the principal source of ecological disturbance investigated in this research.

\section{Methods}

There are two main components to the methodology we used in this research: (1) a DPM constructed in a GIS from aerial photograph-derived polygons of the stream channel, and (2) vegetation data gathered in the field. The DPM estimates the probability that each pixel in the model was occupied by the stream channel during the study's timeframe. Each pixel was classified as having a low, moderate, or high probability of being occupied by the stream channel. We sampled 64 vegetation plots with approximately 21 of them located in each disturbance probability class. These vegetation data allowed us to calculate and compare the mean values of species richness, ground cover, and diversity for each disturbance class.

\section{$D P M$}

Aerial imagery of the limotrophe reach was acquired from the Bureau of Reclamation (Yuma Division) and the Environmental Research Laboratory at the University of Arizona. The images represented six different years spanning 


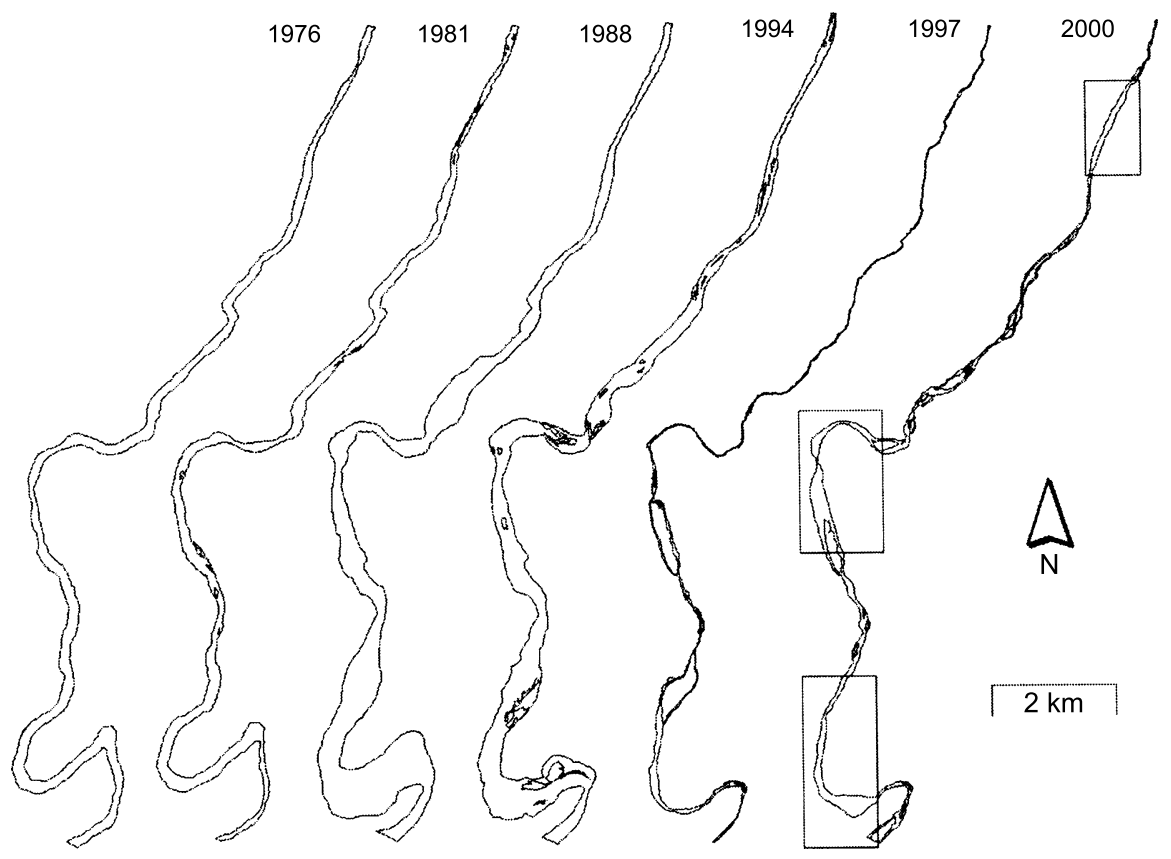

Figure 3. Channel polygons from which the DPM was created. Boxes indicate areas where aerial imagery was unavailable. Channel position within these boxes is only an estimation.

1976-2000 (Figure 3). The year 1976 was the first year prior to 1980 for which aerial imagery of the limotrophe reach was readily available. Photographs were scanned at a resolution of 600 dots per inch, consistent with the method of Graf (2000), which yielded a resolution of approximately $0.4 \mathrm{~m}$.

Each of the approximately 200 aerial photos used in this study was registered to 1991 SPOT satellite imagery provided by the Bureau of Reclamation. This method proved to be more accurate and less labor intensive than using 1:24,000 USGS digital quad sheets as suggested by Graf (2000) because the particular quad sheets utilized had few features in common with the aerial imagery. Features common to both the SPOT imagery and the aerial photos included road intersections, buildings, infrastructure associated with irrigation and trees. For each photograph approximately 35-40 ground control points were used. Each photograph was rectified using bilinear interpolation in ERDAS Imagine and pixel size maintained at $0.4 \mathrm{~m}$.

Digitized polygons of the active channel were created from imagery mosaics. The active channel is defined here as an elongated area where streamflow occurs with sufficient frequency and force to discourage the presence of vegetation such that $90 \%$ or more of this area is bare. Using absence of vegetation rather than a strictly geomorphological approach was used successfully by Gurnell (1995). On-screen digitization was conducted in ERDAS Imagine at a scale of 1:5000. Vegetated mid-channel bars are a common landform of the limotrophe landscape. Those greater than 1.2 ha were digitized and excluded from the active channel. Those smaller than 
1.2 ha, which did not collectively constitute a large portion of the study site, were included as part of the active channel. Precise digitization of areas smaller than $1.2 \mathrm{ha}$ would have necessitated a change in the 1:5000 scale and thus would have compromised methodological consistency. With these techniques a polygon coverage depicting the active channel was created for each photomosaic.

A DPM is a graphic representation of the most likely location and configuration of a stream channel. The DPM used in this study and methods used to create it are closely modeled after the locational probability model of Graf (2000). The DPM can be thought of as an overlay of stream channel polygons where numerical weights $\left(W_{n}\right)$ are assigned to the pixels of each polygon. These weighting values vary positively and proportionally to the number of years represented by the photomosaic from which the polygon was created. These weights allowed an estimate of the amount of time each active channel configuration persisted. The value of these weights was derived in the method of Graf (2000).

$$
W_{n}=\frac{t_{n}}{m},
$$

where $W_{n}$ is equivalent to the number of years represented by the given photograph $\left(t_{n}\right)$ (i.e., the number of years separating it and the preceding photograph) divided by the total number of years in the photographic record $(m)$. Here $m$ is equivalent to 24 (2000-1976), and so:

$$
W_{n}=\frac{t_{n}}{24} .
$$

For example, the active channel polygon for 1994 was assigned a value of 0.25 since six years separate (i.e., $t_{n}=6$ ) the 1994 imagery from that taken in 1988.

Each pixel of the final locational probability map was assigned a $P$-value derived from the equation:

$$
P=\left(W_{1976}\right)+\left(W_{1981}\right)+\left(W_{1988}\right)+\left(W_{1994}\right)+\left(W_{1997}\right)+\left(W_{2000}\right),
$$

where $P$ is the estimated probability that a given pixel was disturbed during the study's timeframe. If a pixel was never occupied by the stream channel and thus was not disturbed it was assigned a $P$-value of 0.00 . If a pixel was occupied by the stream channel in each aerial photograph it acquired a $P$-value of 1.00 .

Once $P$-values were obtained for each pixel they were classified by three equal intervals as having a low (0-33\%), moderate (34-66\%) or high (67-100\%) probability of being disturbed during the timeframe of the study. This classification scheme was chosen over others because it maximized inter-group differences and minimized intra-group differences. The final DPM is shown in Figure 4.

Significant gaps exist in the 2000 aerial imagery due to errors that occurred when these data were being gathered. Approximately $40 \%$ of the study area was not photographically represented in that year. For this area, $P$-values were obtained using the same methods outlined above, with the exception that $W_{2000}$ was not used in the equation for determining $P$-values. For further discussion on the implications of these gaps see Tiegs and Pohl (in press). 


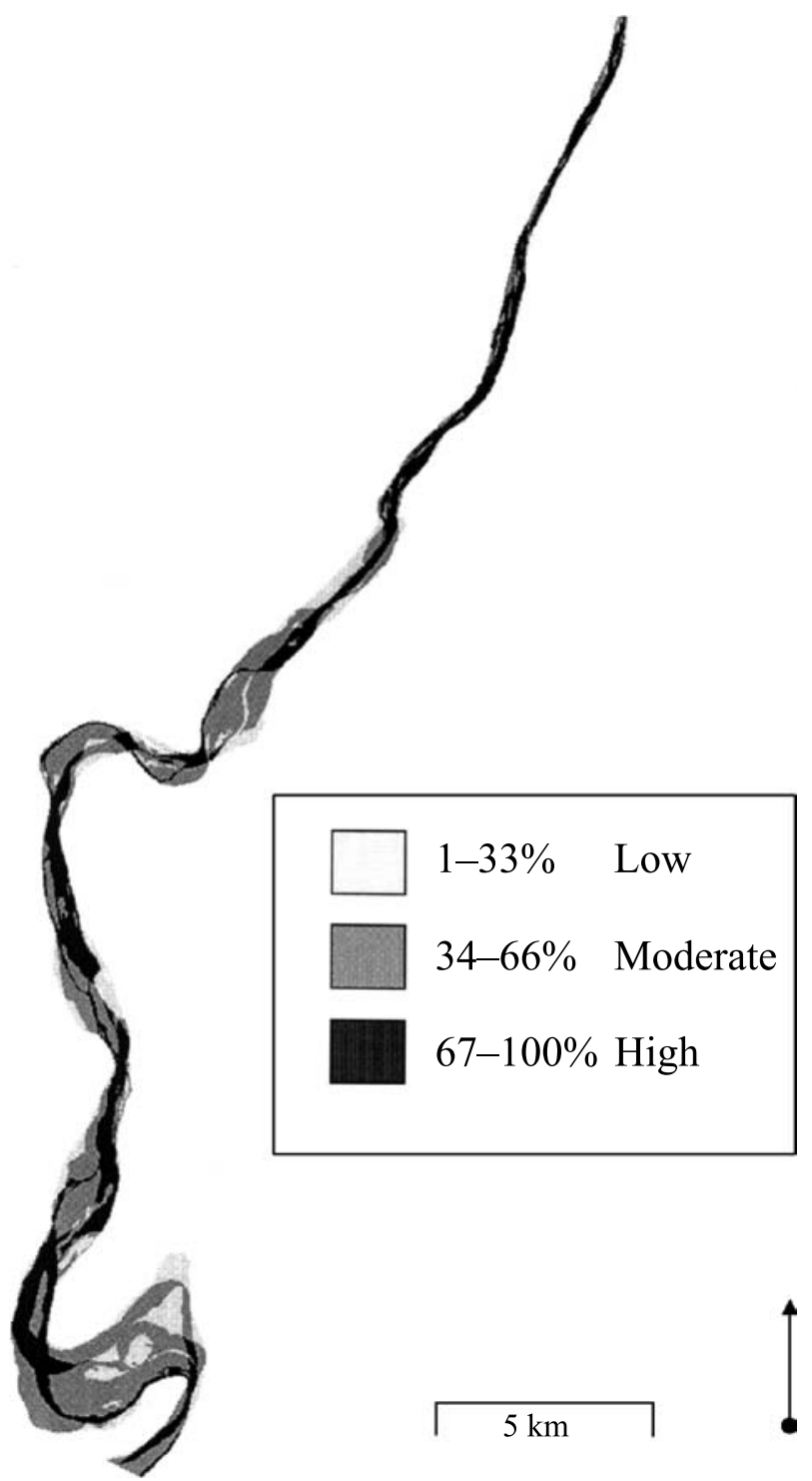

Figure 4. Results from the DPM showing the estimated probability that a given area was occupied by the active channel from 1976 to 2000 .

\section{Vegetation sampling}

Species richness and abundance data were gathered from 64 randomly selected $12 \mathrm{~m} \times 12 \mathrm{~m}$ plots. These data enabled a value of species diversity to be determined for each plot. This value was derived using Shannon's Index (Shannon and Weiner 
1949). Twenty-one plots were surveyed in the low and high probability classes, while 22 plots were surveyed in the moderate disturbance probability class. Within each plot, a list of species was compiled. A tally of this list yielded a species richness value. Species abundance was determined by visually estimating the percent of ground surface within each plot covered by each species. Estimates were made by two observers and averaged for each species on the vast majority of plots sampled. All plots were sampled from March through May, 2002 in order to ensure maximal representation of herbaceous species.

The plot size proposed here is larger than the $100 \mathrm{~m}^{2}$ plot size recommended by Cain and Castro (1959; in Bonham 1989) for surveying vegetation consisting largely of trees. A larger plot size was chosen in response to the often sparse nature of limitrophe reach vegetation. A consequence of larger plot sizes is increased error in estimating vegetation parameters such as frequency of occurrence and percent cover (Bonham 1989). In order to minimize this error, each plot was subdivided into four quadrants with estimations of percent ground cover separately conducted for each $6 \mathrm{~m} \times 6 \mathrm{~m}$ quadrant.

Plot selection was random and stratified by each disturbance group (i.e., low, moderate, and high). This was done in a GIS by draping a $12 \mathrm{~m} \times 12 \mathrm{~m}$ grid over the locational probability model. A numerical value was assigned to each cell in the grid. Random numbers were drawn from a pool equal in size to the number of $12 \mathrm{~m} \times 12 \mathrm{~m}$ plots needed to cover the study area. These numbers corresponded to the vegetation plots we surveyed.

Plot selection was also stratified spatially. Since the floodplain in the southern half of the study reach is much broader than the northern half, most of the riparian area occurs in the southern half. In the absence of spatial stratification, most of the plots would be located in the southern half of the study reach leaving the northern half undersampled. Additionally, in having plots clustered at the southern end of the study area, effects of spatial autocorrelation would likely have been pronounced. To alleviate this condition, an equal number of plots were located within three subreaches of the study site. These sub-reaches were delineated at cross-sections where there was a distinct change in average active channel width. Each of the three subreaches has approximately the same area. An additional effort was made to minimize the effects of spatial autocorrelation by discarding a plot if it occurred within $100 \mathrm{~m}$ of another plot of the same disturbance class. This distance was determined after a test for spatial autocorrelation of species diversity values was performed using Moran's $I$. Moran's $I$ values of two or greater are indicative of significant autocorrelation. Here Moran's $I$ was equal to 0.11 indicating an insignificant amount of autocorrelation.

Once plots were selected we were able to determine the amount of time passed since each plot was occupied by the stream channel (i.e., since it was last disturbed). In order to explore this important idea we sought relationships between species diversity, species richness and percent cover using linear regression analysis. 
The salient difference between the many diversity indices that have been developed is the degree to which they weigh species abundances over species richness. Because of an observed dominance by T. ramosissima in riparian areas of the Colorado River delta, we anticipated that differences in species richness between the three disturbance probablility classes were controlled largely by species abundance. The index developed by Shannon and Wiener (Magurran 1988) was chosen here largely because it stresses abundance over richness (Huston 1994), and thus is useful in comparing communities with few species. Further, the equation proposed by Shannon and Wiener continues to yield the most widely used species diversity index (Huston 1994). The index is calculated using the equation:

$$
H^{\prime}=-\sum\left(p_{i} \ln p_{i}\right),
$$

where $p_{i}$ is the percent ground cover occupied by each plant species in a plot divided by the sum of percent ground cover for all species found in a plot (Magurran 1988).

One-way analysis of variance (ANOVA) with a significance level of 0.05 was used to determine if the mean diversity values, percent ground cover values and richness values among each disturbance group differ significantly. All values for species diversity and species richness were logarithmically transformed $(\ln [x+1])$ to correct for any heteroscedasticity and non-normality (Zar 1999). Percent ground cover values were arcsin transformed (Zar 1999). F-tables were consulted to determine significance among group means. Where significance was found, pair-bypair contrasts were conducted with $t$-tests to identify which of the group means differed significantly from the others. The $t$-test was recommended over other tests for sample populations of fewer than 30 (McGrew and Monroe 2000).

Using linear regression analysis (SPSS 1999) we tested for the strength of the relationship between number of years since last disturbance and species richness, percent ground cover, and species diversity $\left(H^{\prime}\right)$ for both herbaceous species and woody species. Species richness and species diversity values were again logarithmically transformed, and percent ground cover values were arcsin transformed.

\section{Results}

Twenty-two plant species were encountered during vegetation surveys. Despite being low, this value is a reasonable representation of the species-poor communities that typify most of the upper Colorado River delta riparian zone. Of these species, eight are woody (shrubs or trees) and 14 are herbaceous. Table 1 summarizes results of the $6412 \mathrm{~m} \times 12 \mathrm{~m}$ sample plots we surveyed. Sixteen, 12 and 21 species were found in plots of low, moderate and high disturbance probability, respectively. Almost all species we encountered are native with the notable exception of T. ramosissima. Occurring in $94 \%$ of the plots surveyed, T. ramosissima was the most frequently encountered species within each of the three disturbance groups. This exotic and invasive species occupied approximately $18 \%$ of the $9216 \mathrm{~m}^{2}$ surveyed. 


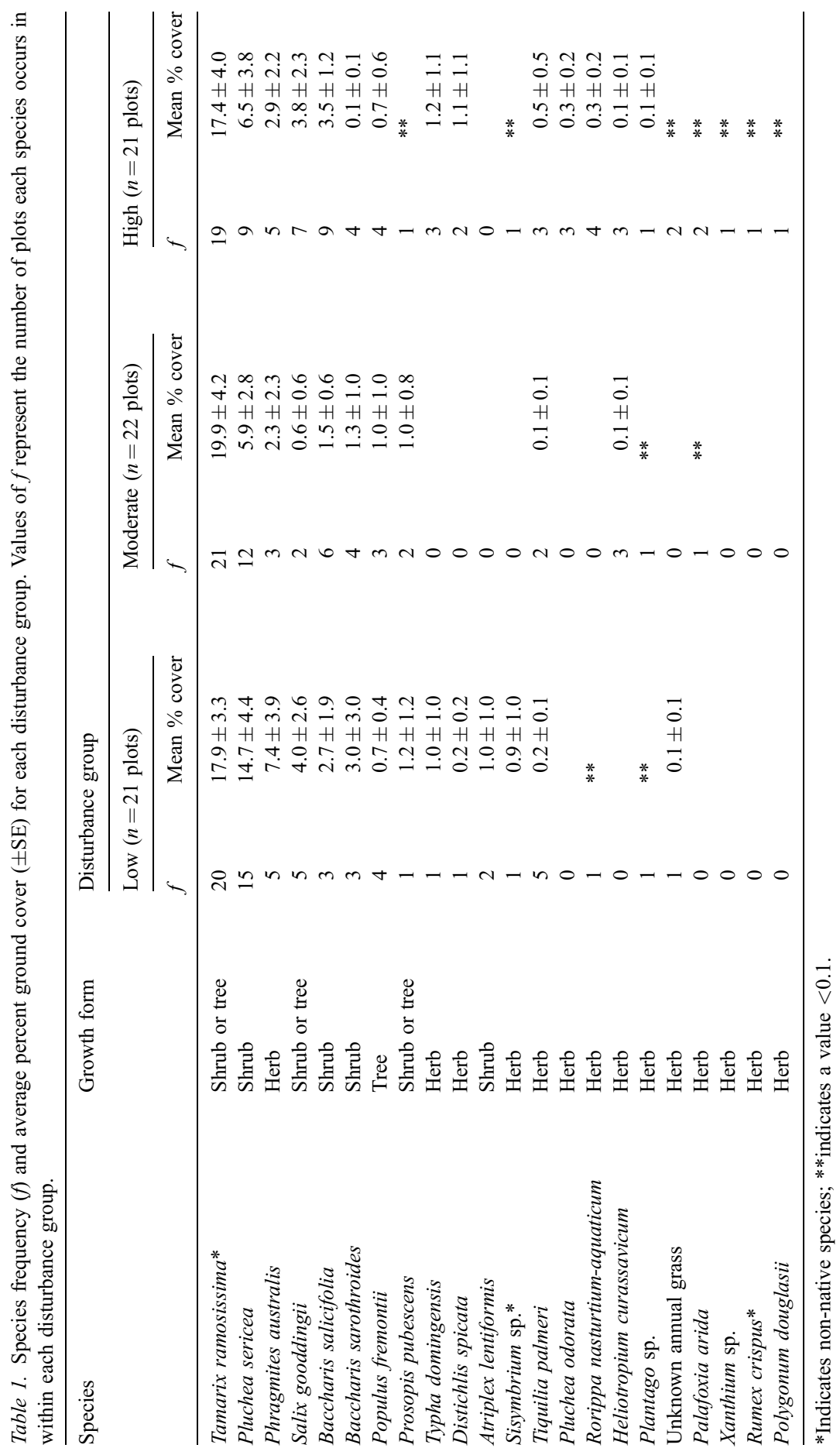


Table 2. Non-transformed mean values $( \pm \mathrm{SE})$ of species richness, percent ground cover, and the Shannon-Wiener index $\left(H^{\prime}\right)$ for each disturbance group for total species (herbs, shrubs, and trees) and for woody species (shrubs and trees).

\begin{tabular}{|c|c|c|c|c|c|c|}
\hline \multirow[t]{2}{*}{ Disturbance group } & \multicolumn{2}{|c|}{ Species richness } & \multicolumn{2}{|c|}{$\%$ Ground cover } & \multicolumn{2}{|l|}{$H^{\prime}$} \\
\hline & Total & Woody & Total & Woody & Total & Woody \\
\hline Low $(n=21)$ & $3.3 \pm 0.4$ & $2.5 \pm 0.2$ & $55.1 \pm 7.8^{\mathrm{a}}$ & $45.2 \pm 6.6$ & $1.13 \pm 0.49$ & $0.55 \pm 0.08$ \\
\hline Moderate $(n=22)$ & $2.6 \pm 0.4$ & $2.2 \pm 0.3$ & $33.9 \pm 5.6^{\mathrm{a}}$ & $31.4 \pm 5.8$ & $0.47 \pm 0.10$ & $0.43 \pm 0.10$ \\
\hline High $(n=21)$ & $4.0 \pm 0.7$ & $2.5 \pm 0.4$ & $38.9 \pm 8.2$ & $32.2 \pm 7.3$ & $0.67 \pm 0.12$ & $0.48 \pm 0.10$ \\
\hline
\end{tabular}

${ }^{\text {a }}$ ignificant difference in means $(P<0.05)$.

Table 3. ANOVA table for total species richness.

\begin{tabular}{lccccc}
\hline Source of variation & Degrees of freedom & Sum of squares & Mean squares & $F$-value & $P$-value \\
\hline Between groups & 2 & 0.69 & 0.35 & 1.41 & 0.25 \\
Within groups & 61 & 15.02 & 0.25 & & \\
Total & 63 & 15.72 & & &
\end{tabular}

Table 4. ANOVA table for woody species richness.

\begin{tabular}{lccccc}
\hline Source of variation & Degrees of freedom & Sum of squares & Mean squares & $F$-value & $P$-value \\
\hline Between groups & 2 & 0.22 & 0.11 & 0.57 & 0.57 \\
Within groups & 61 & 11.79 & 0.19 & & \\
Total & 63 & 12.01 & & & \\
\hline
\end{tabular}

Table 5. ANOVA table for percent ground cover (total species).

\begin{tabular}{lcllll}
\hline Source of variation & Degrees of freedom & Sum of squares & Mean squares & $F$-value & $P$-value \\
\hline Between groups & 2 & 0.80 & 0.40 & 2.71 & 0.07 \\
Within groups & 61 & 9.03 & 0.15 & & \\
Total & 63 & 9.84 & & & \\
\hline
\end{tabular}

Other non-native species were rarely observed. The most frequently encountered native species was Pluchea sericea.

Table 2 shows mean values of richness, percent ground cover and the ShannonWiener Index for both total species and for woody species in each disturbance group. These values and their corresponding variance were used to perform ANOVA tests. Clearly woody species contribute greatest to average species richness, percent ground cover, and species diversity $\left(H^{\prime}\right)$ in each disturbance group.

No overall statistically significant differences were revealed among the disturbance groups for values of species richness, percent ground cover, or the Shannon-Wiener Index (Tables 3-8). However, paired contrasts of means revealed that total percent ground cover on low disturbance plots was significantly higher than on moderately disturbed plots $(55.1 \%$ v.s. $33.9 \%)$ (Table 2$)$. 
Table 6. ANOVA table for percent woody ground cover.

\begin{tabular}{lcllll}
\hline Source of variation & Degrees of freedom & Sum of squares & Mean squares & $F$-value & $P$-value \\
\hline Between groups & 2 & 0.46 & 0.23 & 1.91 & 0.16 \\
Within groups & 61 & 7.40 & 0.12 & & \\
Total & 63 & 7.86 & & & \\
\hline
\end{tabular}

Table 7. ANOVA table for the Shannon-Weiner index $\left(H^{\prime}\right)$ (all species).

\begin{tabular}{lcllll}
\hline Source of variation & Degrees of freedom & Sum of squares & Mean squares & $F$-value & $P$-value \\
\hline Between groups & 2 & 0.58 & 0.29 & 1.89 & 0.16 \\
Within groups & 61 & 9.37 & 0.15 & & \\
Total & 63 & 9.95 & & & \\
\hline
\end{tabular}

Table 8. ANOVA table for the Shannon-Weiner index $\left(H^{\prime}\right)$ for woody species.

\begin{tabular}{lcllll}
\hline Source of variation & Degrees of freedom & Sum of squares & Mean squares & $F$-value & $P$-value \\
\hline Between groups & 2 & 0.12 & 0.06 & 0.73 & 0.49 \\
Within groups & 61 & 4.98 & 0.08 & & \\
Total & 63 & 5.10 & & & \\
\hline
\end{tabular}

Results of the linear regression analysis revealed a significant negative relationship between the number of years passed since last disturbance and species richness $\left(r^{2}=0.122, P=0.005\right)$ (Figure 5(a)), percent ground cover $\left(r^{2}=0.005, P=0.005\right)$ (Figure 5(b)), and species diversity $\left(r^{2}=0.153, P=0.001\right)$ (Figure $5(\mathrm{c})$ ) for herbaceous species. However, the low $r^{2}$ values indicate a weak predictive relationship. Further, we noted no significant difference between number of years passed since last disturbance and species richness $\left(r^{2}=0.01, P=0.432\right)$ (Figure 6(a)), percent ground cover $\left(r^{2}=0.016, P=0.319\right)$ (Figure $\left.6(\mathrm{~b})\right)$, and species diversity $\left(r^{2}=0.0003, P=0.888\right)$ (Figure $\left.6(\mathrm{c})\right)$ for woody species.

\section{Discussion}

Researchers frequently invoke the intermediate disturbance hypothesis (IDH) to explain spatially and temporally variable levels of species diversity observed in nature. According to this hypothesis, ecological disturbances of intermediate size, frequency and intensity promote high species diversity by allowing coexistence of early and late successional species (Connell 1978; Huston 1979). Areas exposed to low and high levels of disturbance harbor relatively fewer species because they are dominated by competitive species and ruderals, respectively.

Areas exposed to moderately frequent flood disturbances did not harbor maximum levels of species diversity, richness or percent ground cover in the time period investigated. Similarly, no meaningful relationship was detected between patch age 

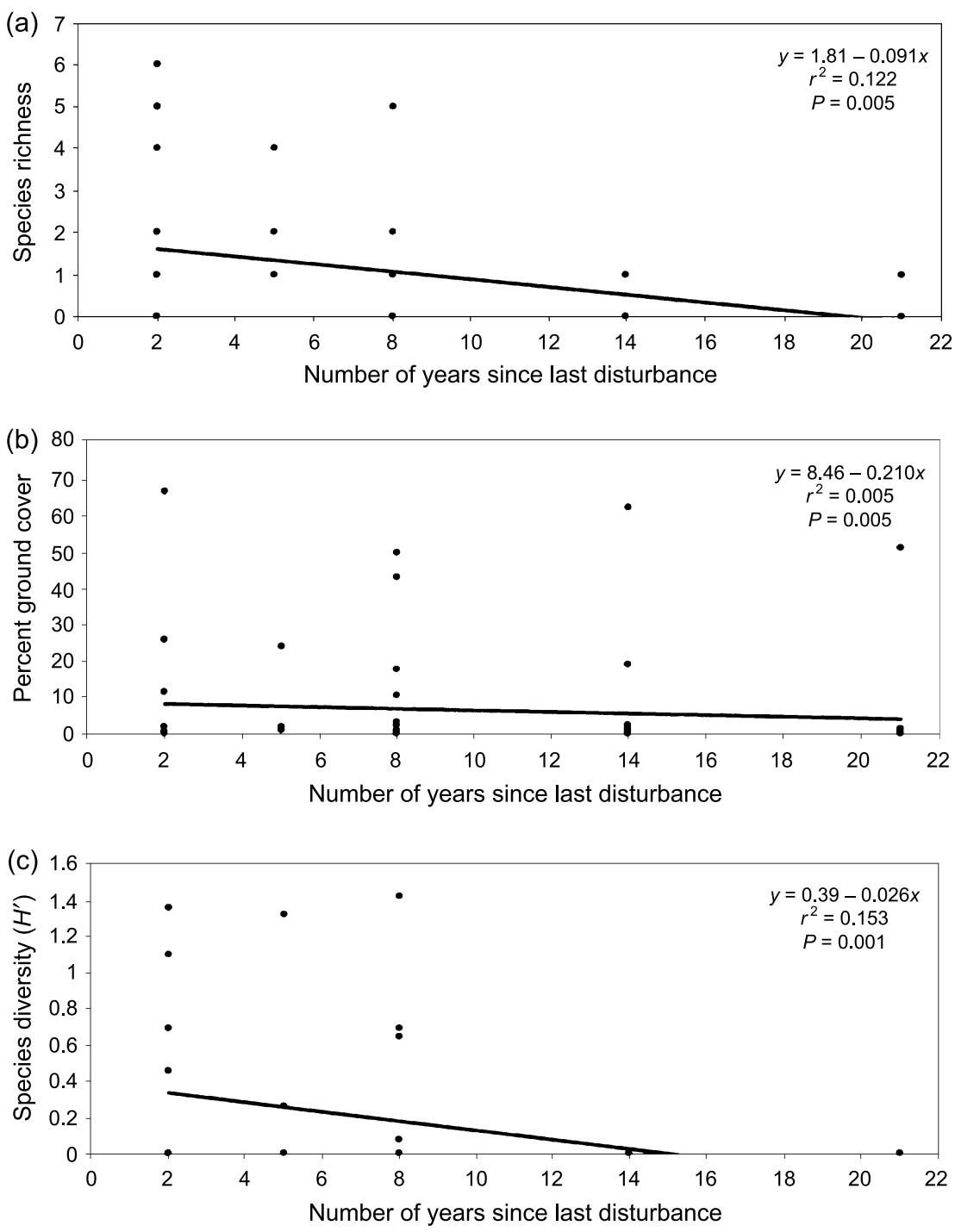

Figure 5. Relationship between number of years since last disturbance and: (a) species diversity, (b) percent ground cover, and (c) species richness for herbaceous species.

and species diversity, richness or percent cover though, amount of time passed since last disturbance is thought to govern species diversity (Connell 1978). Given that riparian vegetation is exposed to a suite of disturbances affiliated with both wetlands and uplands (Johnson 2000), it would seem well suited to investigations of disturbance theory. However, some riparian zones may be inappropriate settings in which to test hypotheses such as the IDH. As originally proposed, the IDH assumes a transition from communities dominated by early seral species to competitive late 

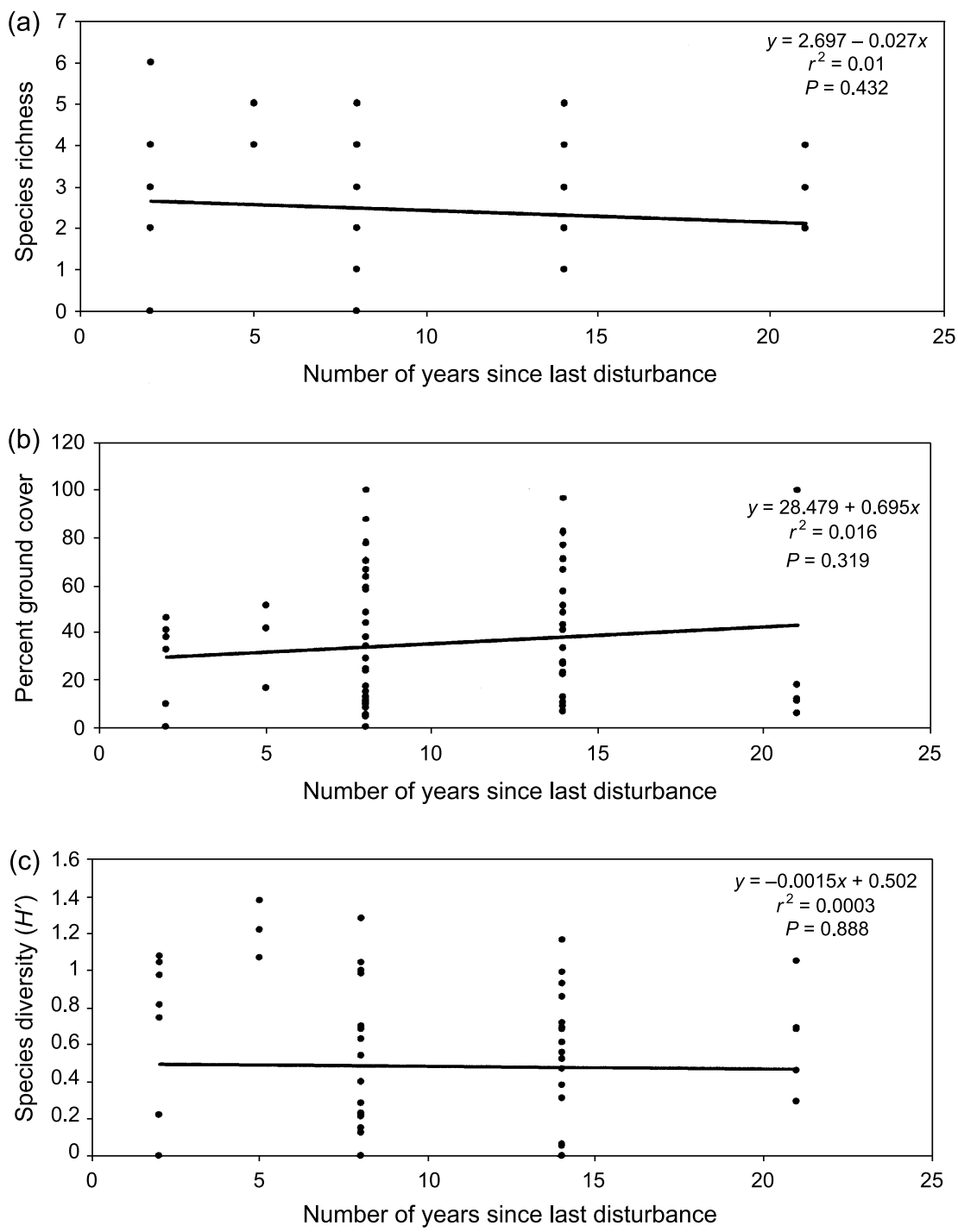

Figure 6. Relationship between number of years since last disturbance and: (a) species diversity, (b) percent ground cover, and (c) species richness for woody species.

seral communities. Given the frequent turnover of dynamic floodplains like those of the Colorado River delta, disturbance frequency may be sufficiently frequent to preclude the establishment of late seral species.

In the case of the limitrophe reach, where most of the current riparian vegetation was restored by flooding subsequent to 1980, little of the vegetation surveyed was older than twenty years. Given the magnitude of the disturbances caused by the El Niño-Southern Oscillation floods of the early and mid-1980s, virtually all of the 
vegetation is less than 20 years old. This may have been an insufficient amount of time for competitive processes to detectably influence levels of diversity. Baker and Walford (1995) noted little difference in riparian richness on the Animas River in Colorado between sites of 10 and 30 years old. Richness, however, increased markedly in sites of approximately 60 years of age. In addition, significant change in community composition was not observed until vegetation had reached an age of approximately 60 years. In light of this, it is perhaps not surprising that site age and disturbance frequency had little influence on species diversity in our investigation. The weakly negative relationship observed in our research can be explained by the relatively few herbs encountered in low disturbance plots. Since high disturbance plots are frequently found near the contemporary stream channel, the relatively large number of herbaceous species observed in high disturbance plots can be explained by their proximity to shallow subsurface moisture.

Figure 4 shows disturbance patches of varying size, shape and degree of connectedness. In general, low disturbance patches appeared large, had high area-toperimeter ratios and were isolated from other low disturbance patches. High disturbance patches appeared small, elongated and well connected to other high disturbance patches. Moderate disturbance patches appeared intermediate in their size and degree of connectedness. Patch size and amount of time since last disturbance are thought to influence species diversity (Connell 1978). Large disturbance patches are more prone to colonization by early-seral, $r$-selected species that release many propagules capable of traveling large distances (Connell 1978). Smaller disturbance patches are more likely to become colonized by competitive species, the propagules of which originate from adults growing near the disturbance patch. Disturbance patch shape, specifically its perimeter-to-area ratio, would seem to govern species diversity in a similar fashion. Elongated disturbance patches, even those of large areas, would seem to be susceptible to colonization by competitive individuals growing near the disturbance patch. The area contained within more circular-shaped disturbance patches would seem to require colonization by species with propagules capable of traveling longer distances. These arguments may be moot, however, given the dominance of the study area by $r$-selected species with wind dispersed propagules capable of traveling large distances (e.g., T. ramosissima, $P$. fremontii).

Although we utilized more direct methods for measuring flood disturbance than much of the past research involving riparian vegetation, our DPM is only an approximation of disturbance frequency. All major floods were bracketed by aerial imagery; however, the aerial photography used in this study was of insufficient frequency to bracket every flood event that occurred since 1976. In instances when two channel polygons bracketed more than one flood event (e.g., between 1997 and 2000) the floods were typically of low magnitude and short duration, and thus the amount of disturbance they induced was likely minimal. These floods likely caused minor channel widening rather than major shifts in channel location and pattern. In the case of the two minor floods of the late 1990s, minor channel widening likely occurred in areas that had only recently been encroached upon by vegetation (i.e., these areas were likely deemed part of the channel on the 1994 
and 1988 aerial imagery). As such, had aerial coverage bracketed these smaller flood events, the likely effect on the DPM would have been to raise the $P$-values of high disturbance areas and thus there would have been no change in the DPM classification.

The role of disturbance as a regulator of species diversity has been shown to play a secondary role to ecological stresses in the presence of river regulation (Cowell and Dyer 2002). Given the extreme aridity of the study area and the high salinity of the agricultural return flows that maintain limitrophe reach vegetation during nonflood years, drought stress due to groundwater decline and salinity likely govern diversity levels. These stressors give competitive advantage to drought tolerant T. ramosissima (Busch and Smith 1995; Glenn et al 1998). This species was shown to outcompete $P$. sericia, B. salicifolia, P. fremontii, and S. gooddingii under conditions of elevated salinity and drought stress (Stromberg 1998; Vandersande et al. 2001). These native species outcompete T. ramosissima, however, under flooded conditions (Stromberg 1998; Vandersande et al. 2001), and thus regardless of the disturbance they induce, frequent floods could govern species diversity by causing flood stress to T. ramosissima and reducing salt stress to native species by alleviating high soil salinity levels.

\section{Conclusions}

Most types of riparian vegetation in the American Southwest now cover only a limited fraction of their former historical range due to human activities such as river damming, discharge regulation, stream water diversions, livestock overgrazing, floodplain development for agriculture and spreading urbanization, and watershed degradation (Stromberg et al. 1996). In particular, aquatic ecosystems of the lower Colorado River have been severely reduced or damaged by these human-related activities (Briggs and Cornelius 1998). Intact riparian ecosystems provide rich concentrations of biodiversity in arid regions. Historic reduction in areal extent and quality of remaining riparian vegetation along the lower Colorado River mainstem and delta has undoubtedly had a negative impact on biodiversity in this area. As a result, some animal species that are riparian obligates have experienced significant population reductions. The southwestern willow flycatcher (Empidonax traillii extimus), western yellow-billed cuckoo (Coccyzus americanus occidentalis), Yuma clapper rail (Rallus longirostris yumanensis), and least Bell's vireo (Vireo bellii pusillus) are endangered species on the U.S. federal list that occur in the overall study area (Unitt 1987; Kus 1998).

Native plant species of the Colorado River delta have benefited largely from flood events in recent decades (Glenn et al. 1996, 2001; Stromberg 2001). Despite results of this research that suggest flood disturbance does not play a major role in governing diversity levels between disturbance classes, these floods have likely elevated gamma diversity (i.e., regional plant diversity) in the study area over the past two decades. Although the contemporary hydrologic regime of the Colorado River delta more closely approximates the pre-dam regime, it is an approximation nonetheless. 
If the hydrologic regime of the delta continues to gravitate towards the pre-dam condition, future research may observe that disturbance plays an important role in regulating riparian diversity. On the contemporary Colorado River delta, variability in riparian species diversity through time and space appears to hinge on factors other than disturbance frequency, such as salt or drought stress.

Stromberg and Chew (2002) advocate the role of flood pulses as a restorative management strategy for improving plant productivity, management of exotic species (particularly T. ramosissima), and restoration of overall biodiversity. The ecological gain acquired from intentional flood discharges can be maximized by exploiting the physiologic, reproductive and habitat differences between T. ramosissima and desirable riparian species such as $P$. fremontii and $S$. gooddingii. Conditions of high soil salinity coupled with drought stress to the riparian vegetation of the delta appear to benefit T. ramosissima at the expense of native plant species. Future flood releases to the delta, whether incidental or intentional, will certainly improve native habitats and overall biodiversity. These floods will reduce the competitive ability of $T$. ramosissima by providing native species with elevated water tables and flushing accumulated salts from the soil. The timing of flood disturbances caused by intentional floods could encourage native species and discourage $T$. ramosissima, given that $P$. fremontii and $S$. gooddingii release their propagules at different months of the year than T. ramosissima. Such discharge pulses would also serve to restore herbaceous biodiversity by providing moisture to various herbaceous species whose life histories are critically dependent on the natural flow regime. Further, pulse discharges play an important geomorphic role in promoting patchy deposition of fine- and coarse-grained sediments that are differentially exploited by various herbaceous species.

Results of this research question the importance of disturbance level in regulating species diversity in our overall study area. Alternatively our results could be interpreted as suggesting that in the presence of intensive flow regulation, disturbance plays a secondary role to ecological stresses similar to that demonstrated by Cowell and Dyer (2002). If this latter view is adopted, there is a clear need for a more naturalized flow regime on the Colorado River delta. More frequent flood pulses will benefit native plant communities at the expense of T. ramosissima. Further, in the presence of a more naturalized hydrologic regime, future research may observe that the role of disturbance displaces that of stress as a governor of riparian diversity and overall habitat.

\section{Acknowledgements}

We thank Jennifer Paluch, Jonathan Snap-Cook, and Mark Tucker for assistance with field work, and Michael White, Phil Pryde, and two anonymous reviewers for helpful suggestions on an earlier draft of the manuscript. We also thank Harry Johnson for cartographic assistance and for GIS assistance in working with the DPM. Project funding by a Clair A. Hill Scholarship awarded to S.D.T. by the Association of California Water Agencies is gratefully acknowledged. 


\section{References}

Baker W.L. and Walford G.M. 1995. Multiple stable states and models of riparian vegetation succession on the Animas River, Colorado. Annals of the Association of American Geographers 85: 320-338.

Barnes W.J. 1997. Vegetation dynamics on the floodplain of the lower Chippewa River in Wisconsin. Journal of the Torrey Botanical Club 124: 189-197.

Bendix J. 1997. Flood disturbance and the distribution of riparian species diversity. The Geographical Review 87: 468-483.

Bonham C.D. 1989. Measurements for Terrestrial Vegetation. John Wiley \& Sons, New York.

Briggs M.K. and Cornelius S. 1998. Opportunities for ecological improvement along the lower Colorado River and delta. Wetlands 18: 513-529.

Busch D.E. and Smith S.D. 1995. Mechanisms associated with decline of woody species in riparian ecosystems of the southwestern U.S. Ecological Monographs 65: 347-370.

Cain S.A. and Castro G.J.de O. 1959. Manual of Vegetation Analysis. Harper, New York.

CIMIS 2002. California Irrigation Management Information System. Imperial Valley Data, www.dpla. water.ca.gov/cimis/cimis/hq/1-2002.

Cohen M.J., Henges-Jeck C. and Castillo-Moreno G. 2001. A preliminary water balance for the Colorado River Delta, 1992-1998. Journal of Arid Environments 49: 35-48.

Connell J.H. 1978. Diversity in tropical rainforests and coral reefs. Science 199: 1302-1310.

Cowell C.M. and Dyer J.M. 2002. Vegetation development in a modified riparian environment: human imprints on an Allegheny River wilderness. Annals of the Association of American Geographers 92: 189-202.

Decamps H. and Tabacci E. 1992. Species richness in vegetation along river margins. In: Giller P.S., Hildrew A.G. and Hildrew D.G. (eds) Aquatic Ecology: Scale, Pattern and Process. Blackwell Scientific Publications, Oxford, UK, pp. 1-20.

Deiller A.F., Walter J.N. and Tremolieres T. 2001. Effects of flood interruption on species richness, diversity and floristic composition of woody regeneration in the Upper Rhine alluvial hardwood forest regulated rivers. Research and Management 17: 393-405.

Glenn E.P., Lee C., Felger R. and Zengel S. 1996. Effects of water management on the wetlands of the Colorado River Delta, Mexico. Conservation Biology 10: 1175-1186.

Glenn E., Tanner R., Mendez S., Kehret T., Moore D., Garcia J. et al. 1998. Growth rates, salt tolerance and water use characteristics of native and invasive riparian plants from the delta of the Colorado River, Mexico. Journal of Arid Environments 40: 281-294.

Glenn E.P., Zamora-Arroyo F., Nagler P.L., Briggs M., Shaw W. and Flessa K. 2001. Ecology and conservation biology of the Colorado River Delta, Mexico. Journal of Arid Environments 49: $5-15$.

Graf W.L. 2000. Locational probability for a dammed, urbanizing stream: Salt River, Arizona, USA. Environmental Management 25: 321-335.

Gurnell A.M. 1995. Vegetation along river corridors: hydrogeomorphological interactions changing river channels. In: Gurnell A.M. and Petts G.E. (eds) Changing River Channels. John Wiley and Sons, Chichester, UK, pp. 237-260.

Hickman J.C. (ed) 1993. The Jepson Manual. Higher Plants of California. University of California Press, Berkeley, California.

Huston M. 1979. A general hypothesis of species diversity. The American Naturalist 113: 81-101.

Huston M. 1994. Biological Diversity. Cambridge University Press, Cambridge, UK.

Johnson W.C. 2000. Tree recruitment and survival in rivers: influence of hydrological processes. Hydrological Processes 14: 3051-3074.

Kus B.E. 1998. Use of restored riparian habitat by the endangered Bell's vireo. Restoration Ecology 6: 75-82.

Luecke D., Pitt J., Congdon C., Glenn E., Valdes-Casillas C. and Briggs M. 1999. A Delta Once More: Restoring Riparian and Wetland Habitat in the Colorado River Delta. Environmental Defense Fund Publications, Washington, DC. 
Mackey R.L. and Currie D.J. 2001. The diversity-disturbance relationship: is it generally strong and peaked? Ecology 82: 3479-3492.

Magurran A.E. 1988. Ecological Diversity and Its Measurement. Princeton University Press, Princeton, New Jersey.

Malanson G.P. 1993. Riparian Landscapes. Cambridge University Press, Cambridge, UK.

McGrew J.C. and Monroe C.B. 2000. An Introduction to Statistical Problem Solving in Geography. McGraw-Hill, Boston, Massachusetts.

Muller E. 1997. Mapping riparian vegetation along rivers: old concepts and new Methods. Aquatic Botany 58: 411-437.

Naiman R.J., Decamps H. and Pollock M. 1993. The role of riparian vegetation in maintaining regional biodiversity. Ecological Applications 3: 209-212.

Nilsson C., Grelsson G., Johansson M. and Sperens U. 1988. Can rarity and diversity be predicted in vegetation along river banks? Biological Conservation 44: 201-212.

Nilsson C., Grelsson G., Johansson M. and Sperens U. 1989. Patterns of species diversity along riverbanks. Ecology 70: 77-84.

Nilsson C., Ekbland M., Gardfjell M. and Carlberg B. 1991. Long-term effects of river regulation on river margin vegetation. Journal of Applied Ecology 28: 963-987.

Patten D.T. 1998. Riparian ecosystems of semi-arid North America: diversity and human impacts. Wetlands 18: 498-512.

Pitt J., Luecke D., Cohen M., Glenn E. and Valdes-Casillas C. 2000. Two nations, one river: managing ecosystem conservation in the Colorado River Delta. Natural Resources Journal 40: 819-865.

Poff N.L., Allan J.D., Bain M.B., Karr J.R., Prestegaard K.L., Richter B.D. et al. 1997. The natural flow regime. Bioscience 47: 769-784.

Pollock M.M., Naiman R.J. and Hanley T.A. 1998. Plant species richness in riparian wetlands - a test of biodiversity theory. Ecology 79: 94-105.

Shannon C.E. and Wiener W. 1949. The Mathematical Theory of Communication. University of Illinois Press, Urbana, Illinois.

SPSS 1999. SYSTAT 9. SPSS Inc., Chicago, Illinois.

Stromberg J.C. 1998. Dynamics of Fremont cottonwood (Populus fremontii) and salt Cedar (Tamarix chinensis) populations along the San Pedro River, Arizona. Journal of Arid Environments 40: $133-155$.

Stromberg J.C. 2001. Restoration of riparian vegetation in the southwestern United States: importance of flow regimes and fluvial dynamism. Journal of Arid Environments 49: 17-34.

Stromberg J.C. and Chew M.K. 2002. Flood pulses and restoration of riparian vegetation in the American Southwest. In: Middleton B.A. (ed.) Flood Pulsing in Wetlands: Restoring the Natural Hydrological Balance. John Wiley and Sons, New York, pp. 11-49.

Stromberg J.C., Tiller R. and Richter B. 1996. Effects of groundwater decline on riparian vegetation of semiarid regions: the San Pedro River. Ecological Applications 6: 113-131.

Sykes G. 1937. The Colorado Delta. Kennikat, Port Washington, New York.

Tiegs S.D. and Pohl M. Planform channel dynamics of the lower Colorado River: 1976-2000. Geomorphology (in-press)

Unitt P. 1987. Empidonax traillii extimu: an endangered subspecies. Western Birds 18: 137-162.

USGS 1989. Guide for Selecting Manning's Roughness Coefficients for Natural Channels and Flood Plains. United States Geological Survey Water-Supply Paper 2339. USGS, Denver, Colorado.

Vandersande M.W., Glenn E.P. and Walworth J.L. 2001. Tolerance of five riparian plants from the Lower Colorado River to salinity, drought and inundation. Journal of Arid Environments 49: 147-159.

Ward J.V. 1998. Riverine landscapes: biodiversity patterns, disturbance regimes and aquatic conservation. Biological Conservation 83: 269-278.

Zamora-Arroyo F., Naglel P.L., Briggs M., Radtke D., Rodriquez H., Garcia J. et al. 2001. Regeneration of native trees in response to flood releases from the United States into the delta of the Colorado River, Mexico. Journal of Arid Environments 49: 49-64.

Zar J.H. 1999. Biostatistical Analysis. 4th edn. Prentice Hall, Upper Saddle River, New Jersey. 